\title{
Promotion of allogeneic parathyroid cell transplantation in rats with hypoparathyroidism
}

\author{
Zihao Niu ${ }^{1 \#}$, Shuixian Huang ${ }^{2 \#}$, Wen Gao ${ }^{1}$, Gaofei Yin ${ }^{1}$, Wei Guo ${ }^{1}$, Junwei Huang ${ }^{1}$, Yang Zhang ${ }^{1}$, \\ Zhigang Huang ${ }^{1}$
}

${ }^{1}$ Department of Otolaryngology Head and Neck Surgery, Beijing Tongren Hospital, Capital Medical University, Beijing, China; ${ }^{2}$ Department of Otolaryngology Head and Neck Surgery, Gongli Hospital of Pudong New Area, Shanghai, China

Contributions: (I) Conception and design: Y Zhang; (II) Administrative support: Z Huang, Y Zhang; (III) Provision of study materials or patients: Z Niu, Y Zhang; (IV) Collection and assembly of data: Z Niu, S Huang; (V) Data analysis and interpretation: W Guo, J Huang; (VI) Manuscript writing: All authors; (VII) Final approval of manuscript: All authors.

"These authors contributed equally to this work.

Correspondence to: Yang Zhang; Zhigang Huang. Department of Otolaryngology Head and Neck Surgery, Beijing Tongren Hospital, Capital Medical University, Beijing 100730, China. Email: zhangyangent@163.com; huangzhigang1963@sohu.com.

Background: This study sought to establish a rat model of hypoparathyroidism by removing the rat parathyroid glands, and compare the effects of different transplantation sites and transplantation methods using a primary culture of parathyroid cells in vitro on the hormone secretion of the model rats.

Methods: Male Sprague Dawley (SD) rats were selected for in vivo parathyroid gland removal, and rats with abnormal postoperative water intake, weight gain, parathyroid hormone (PTH), and blood calcium ion concentration were selected as transplant recipients and divided into the model group, brachioradialis muscle cell transplantation group, gelatin sponge group, and subcutaneous transplantation group. The parathyroid tissue was removed and the primary cell culture was performed in vitro using homozygous SD rats as graft donors. When the parathyroid cells were able to secrete PTH, transplantation was performed, and the postoperative recovery of the PTH function of the rats with different transplantation sites and methods were observed.

Results: A recipient model with low PTH was successfully established, and parathyroid progenitor cells with obvious PTH secretion were obtained. Better secretion was observed in the brachioradialis cell group compare with other groups.

Conclusions: The in vitro primary cell culture of the donor parathyroid cells combined with cell transplantation significantly improved the physiological function of the hypoparathyroid rats, and could potentially replace traditional clinical brachioradialis muscle tissue transplantation.

Keywords: Parathyroid; allogeneic transplantation; primary cell culture

Submitted Nov 05, 2021. Accepted for publication Dec 16, 2021.

doi: 10.21037/gs-21-809

View this article at: https://dx.doi.org/10.21037/gs-21-809

\section{Introduction}

The parathyroid glands are 2 pairs of brownish-yellow, soy-like endocrine glands located (or buried) in the middle and lower parts of the dorsal thyroid glands of the left and right lobes of the body, which regulate the organism's blood calcium and phosphorus concentrations by secreting parathyroid hormone (PTH) (1). The parathyroid gland is the most important regulator of calcium and phosphorus metabolism in the body. In radical thyroid cancer surgery, parathyroid glands are often removed or damaged due to the removal of thyroid cancer tissue and lymphatic dissection, which affects the blood supply to the parathyroid glands, resulting in insufficient PTH secretion and low blood 
calcium (2), which then leads to multiple system damages of the skeletal and cardiovascular system, nervous system, immune system, and skin, etc. $(3,4)$. Normally, treatments for hypoparathyroidism include pharmacotherapy and surgical therapy. Calcium and vitamin D analogs are commonly used drugs for patients with hypoparathyroidism (5). Besides, the development of PTH replacement therapy reduces the dependence on calcium and vitamin D analogs; thus, lowering urinary calcium and renal calcification risks and improving the patient's quality of life (6). For permanent hypoparathyroidism, clinicians have addressed this problem in the traditional way by reinserting the removed parathyroid tissue into the bilateral muscle tissue of the neck after simple shearing $(7,8)$. Nevertheless, survival after the re-transplantation is often poor due to partial loss of parathyroid function caused by cancer. As an effective treatment, parathyroid transplantation is an ideal way for patients to obtain the necessary physiological calcium levels (9). But it could be affected by many factors, such as the transplantation method, transplantation site, and graft selection. The treatment method has been explored for nearly a century, and various transplantation ways such as allogeneic transplantation, microencapsulation, and stem cell therapy have been developed (10-12). Cui and colleagues (13) established a mice model as the co transplantation with adipose-derived cells and indicated that adipose-derived stem cells (ADSCs) induced tubule formation and migration of human endothelial cells in vitro. Furthermore, stromal vascular fractions (SVFs) improved rat parathyroid transplantation survival and blood vessel assembly. Nawrot et al. (14) collected parathyroid tissue from 85 patients who underwent parathyroidectomy due to secondary hyperparathyroidism. The cultured parathyroid cells were cultured and frozen in vitro for 6 weeks. Allogeneic parathyroid cells were transplanted 116 times in the forearm of 85 patients. The average survival time of the transplanted cells was $(6.35 \pm 13.08)$ months, and $55.1 \%$ of the transplanted cells could maintain normal endocrine function for more than 2 months.

However, the current transplantation methods all have certain shortcomings in maintaining the long-term or even permanent survival and functional status of the grafts. Moreover, the prognostic effects of different transplantation sites to select treatment options for hypoparathyroidism need further exploration. In the current study, we hypothesized an allogeneic in vitro cell culture-based transplantation alternative to the existing transplantation methods may increase the survival rate of the parathyroid.
From the perspective of clinical applicability, we focused on exploring a method that is safe, easy to obtain materials, and not prone to transplantation rejection. In this experiment, a rat model with parathyroid hypoplasia was established, cultured primary parathyroid cells in vitro, and then performed allogeneic parathyroid transplantation after the cells became secretory. In terms of transplantation sites, the main clinically commonly used muscles are the sternocleidomastoid muscle, forearm brachioradialis muscle, anterior cervical muscle, and the tibialis anterior muscle (15). Since the brachioradialis muscle of the forearm is convenient for graft function evaluation and has the advantages of easily positioning $(16,17)$, we use this site as one of the options for cell transplantation and do further research. By optimizing the transplantation site of the rat parathyroid gland and introducing gelatin sponge, an absorbent material commonly used in clinical practice, to support cell growth in vivo, the effects of different transplantation sites and transplantation methods on the survival rate and survival period of postoperative parathyroid grafts were examined to provide an effective basis for clinical treatment. We present the following article in accordance with the ARRIVE reporting checklist (available at https://dx.doi.org/10.21037/gs-21-809).

\section{Methods}

\section{Animal model preparation}

Experiments were performed under a project license [No. SCXK (Beijing) 2019-0008] granted by the Ethics Committee of the Beijing Tongren Hospital, Capital Medical University, in compliance with the principles of the National Institutes of Health guide for the care and use of laboratory animals. A protocol was prepared before the study without registration. Thirty-six male Sprague Dawley (SD) rats, aged 6-8 weeks and weighing 150-180 g, were purchased from Beijing Vital River Laboratory Animal Technology Co., Ltd (animal qualification number No. 110011200105820483). The feeding environment was specific pathogen free (SPF) grade. The corresponding. laboratory animal facilities continued to maintain barrier environmental standards. The control range of the main environmental indicators were as follows: room temperature: $20-26{ }^{\circ} \mathrm{C}$, relative humidity: $40-70 \%$, minimum air change: 15 times/hour, and light illumination: dark $=12 \mathrm{~h}: 12 \mathrm{~h}$. The animals were kept in polypropylene rat group cages with cage specifications of 545 by 395 by 
$200 \mathrm{~mm}^{3}$ with 6 rats per box. The feeding space was in line with the minimum space required by the National Standard of the People's Republic of China (GB149252010). The animals were managed by trained and qualified personnel. During the whole feeding process, the animals had free access to food and drink. The feed met the requirements of the nutritional composition of compound feed for experimental animals (GB14924.3-2010), the hygienic standard for compound feed for experimental animals (GB14924.2-2001), and the hygienic standard for compound feed for experimental animals (GB14924.22001). The drinking water was tested in accordance with the sanitary standard of drinking water (GB 5749-2006).

After chloral hydrate anesthesia, the rat was placed in the supine position and the skin was prepared by shaving. The area to be incised was disinfected by wiping with cotton balls soaked in alcohol. Under the operating light, the skin was cut along the median line of the rat's neck using a sterile surgical operation method, and the submaxillary glands on both sides were bluntly separated with forceps. The muscle above the trachea was cut with an incision of about $5 \mathrm{~mm}$ long. To expose the thyroid tissue, micro forceps were used to pull the muscle perpendicularly to the trachea. $2 / 3$ of the thyroid tissue containing the parathyroid glands was removed with ophthalmic scissors, and the bleeding was stopped by gelatin sponges compression. The bilateral parathyroid glands were taken from each rat, and the wound was sutured layer by layer at the end of the experiment and disinfected with iodine. The rats were observed for 2 hours after the operation for awakening. The parathyroid gland tissues of 2 random rats were removed during the experiment, fixed with fixative solution, and sent for examination at the end of the experiment. On days 5 and 10 after surgery, blood was taken from the tail tip to test the serum calcium and PTH levels. Twenty-four of the rats were selected as subsequent transplant recipients according to the experimental results.

\section{In vitro primary culture of parathyroid cells}

Parathyroid tissue derived from 30 donors was removed aseptically, placed in pre-cooled normal saline at $4{ }^{\circ} \mathrm{C}$, rinsed twice, and then placed in $2 \mathrm{mg} / \mathrm{mL}$ of type II collagenase. The tissue pieces were shredded as much as possible with microscope shears, and transferred to a constant temperature incubator at $37^{\circ} \mathrm{C}$ for 90 minutes' digestion. When few intercellular adhesions were observed under the microscope and the separation was obvious, complete
Dulbecco's Modified Eagle Medium (DMEM) (containing $10 \%$ fetal bovine serum, $100 \mathrm{U} / \mathrm{mL}$ of penicillin, and $100 \mu \mathrm{g} / \mathrm{mL}$ of streptomycin) was added to terminate the digestion. The mixture was centrifuged at $1,000 \mathrm{r} / \mathrm{min}$ for 4 mins, and the supernatant was removed. The cell concentration was adjusted to $1 \times 10^{5}$ cells $/ \mathrm{mL}$, and $1 \mathrm{~mL}$ was taken into a T25 culture flask containing $10 \%$ serum in DMEM. The culture flasks were placed in an incubator at $37{ }^{\circ} \mathrm{C}, 95 \%$ air, and $5 \%$ carbon dioxide for thermostatic incubation. When the fusion rate of the cultured cells reached $80 \%$, passages were performed at a ratio of 1:2. Starting from the second generation, the medium was changed to an Endothelial cell medium (ECM)-specific medium to enhance the PTH secretion of parathyroid cells and promote cell growth. The cells were cultured up to day 9 , and cell supernatant was then taken for the PTH content assay.

\section{Determination of sample size}

The preliminary results showed that the cells obtained from the bilateral parathyroid tissue in the primary culture in vitro from 6 rats were suitable for the transplantation of 6 rats. If the number of rats had been increased, the number of cells obtained in vitro would have differed to the number of recipient animals, unless it was a multiple of 6 . However, we elected to make a preliminary comparison of constituent differences with the group of 6 recipient animals. When grouping, the maximum and minimum values of each index were eliminated with the mean values of body weight, serum PTH, and serum calcium ion concentration as references, and no difference was found between the groups. The whole process was carried out using an Excel table and the auxiliary link formula. All the animal experiments in the study were conducted in accordance with the internal ISO9001 quality management standards (i.e., ear labels were used for each rat to avoid confusion). Additionally, each group of cages had a unique identification number. In the process of data recording, the form used to record the data corresponded to the name and ear labels of each group of cages. During the experiment, the cage number and rat ear label data were recorded according to standard operating procedure (SOP), and finally sent to the data entry staff for data entry. After data entry, the quality assurance (QA) staff checked the data, and statistical software was used to analyze the results. Finally, the data were sent to the project leader for group correspondence to ensure no subjectivity in the process. 


\section{Parathyroid allogeneic transplantation}

The experiment comprised 36 animals (6 normal control animals, and 30 rats that were screened after parathyroidectomy). Ultimately, 24 experimental animals were included in the experiment, and divided into the model group, brachioradialis cell transplantation group, subcutaneous transplantation group, and gelatin sponge transplantation group, with 6 rats in each group $(n=6)$.

Subcutaneous transplantation group: When the primary parathyroid cell culture had passed to the third generation with a $80 \%$ fusion rate, the cells were digested, and the cell precipitate was collected by centrifugation. The cell precipitate was rinsed twice with normal saline, and the cell concentration was adjusted to $1.5 \times 10^{6}$ cells $/ \mathrm{mL}$, with a cell injection volume of $0.5 \mathrm{~mL}$ per recipient rat. Gelatin sponge group: during the surgical operation, the skin of the rat's right abdomen was first prepared and disinfected, a 0.5 -cm-long incision was then made with surgical scissors. A $0.5 \mathrm{~cm}$ by $0.5 \mathrm{~cm}$ block of gelatin sponge was delivered to the inoculation site with straight-tipped forceps. The inoculation site was located $1 \mathrm{~cm}$ from the opening site, and the incision was closed with surgical sutures before the cell suspension was injected into the gelatin sponge. The rats in the right arm brachioradialis cell transplantation group were injected with $0.25 \mathrm{~mL}$ of cell suspension on each side of the forearm. Parathyroid cells were obtained and injected in the same amount as that of the subcutaneous transplantation group.

\section{Measurement of biochemical and other indicators}

PTH and blood calcium levels in parathyroid cell supernatant and animal serum were measured according to the enzyme-linked immunoassay kit operating instructions. Diet, water intake, and body weight measurements of the model animals were performed regularly during the experimental period.

\section{Animal care and busbandry}

Sample collection was carried out on the experimental animals in a safe and humane manner. For the dying animals, the veterinarian and the project manager euthanized them according to the Ethics Committee's requirements and SOP procedures. The experimental animals were put to death in accordance with humanitarian principles. No other animals were present at the execution.
After the animal was confirmed dead, the carcass was disposed of properly. The humane end point occurred after all the program indicators had been collected.

\section{Statistical analysis}

Overall measures are expressed as means and standard deviations. The statistical tests were performed using a one-way analysis of variance (ANOVA) in SPSS 22.0 (version 22.0; IBM Corporation, Armonk, NY, USA). The graphs were made using GraphPad Prism 8. SPSS software was input to determine whether the variance met the experimental requirements, and a one-way ANOVA was performed after the requirements were met. For all analyses, statistical significance was set at $\mathrm{P}<0.05$, and all tests were two-sided.

\section{Results}

The average daily water intake, body weight, body weight growth rate, and serum PTH and calcium levels were lower in the parathyroid group than the normal group. The difference in water intake became obvious on days 6 and 10 post operation (Figure $1 A$ ), In the first 5 days after operation, the difference in food intake was significant, and then the difference gradually decreased (Figure 1B), the difference in body weight growth rate disappeared on day 6 post operation (Figure 1C,1D), and the difference in serum PTH and calcium levels was most significant on days 5 and day 9 post operation, especially day 5 (Figure $1 E, 1 F$ ). The animal model of hypoparathyroidism was successfully established.

Two parathyroid glands removed from the model animals were randomly selected for paraffin embedding and hematoxylin and eosin staining. As Figure 2 shows, the parathyroid tissue located lateral to the thyroid gland was visible under the microscope with clear boundaries and dominated by clusters of lightly stained cells with broad cytoplasm and abundant blood sinuses, indicating that the removed tissue was a parathyroid gland.

The primary cell culture was performed after the removal of the donor parathyroid gland. By day 6 of the cell culture, uniform cell morphology and good cell fusion were observed microscopically (Figure $3 A$ ). On day 9 , the cell density further increased and the cells were fused (Figure 3B). The cell supernatant was then taken for the PTH assay. Parathyroid cells with PTH-secretion were obtained (Figure 3C).

Weight, serum PTH values, serum calcium ion 

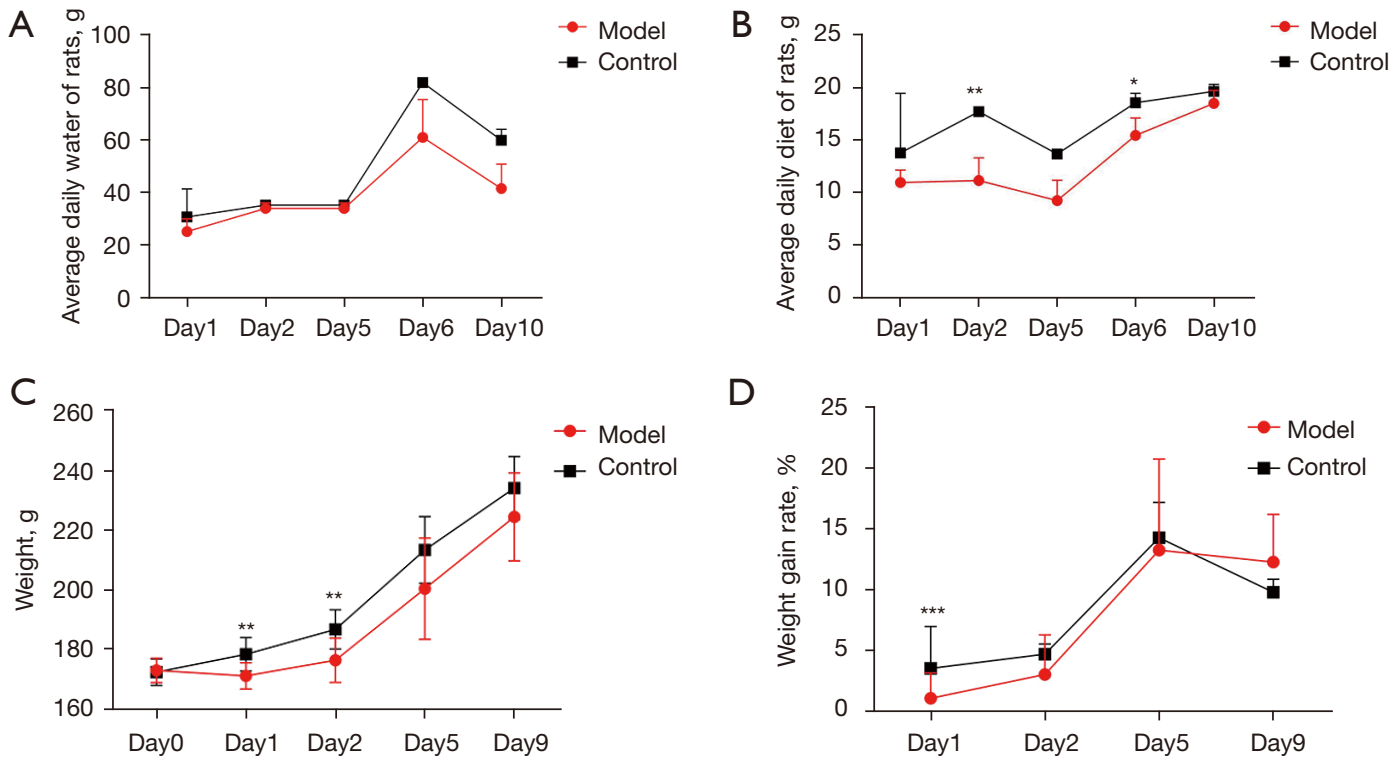

D
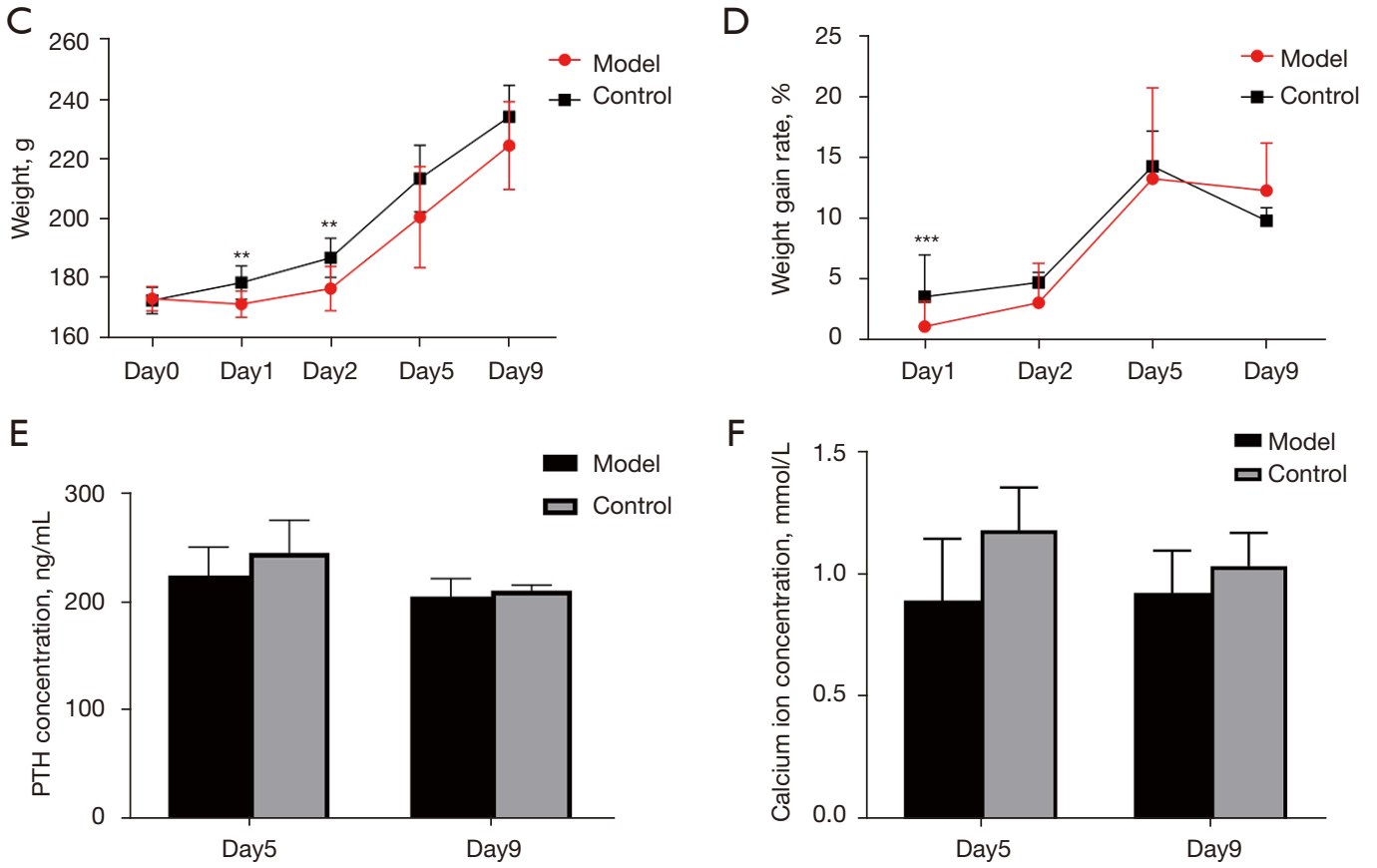

Figure 1 Establishment of animal models with hypoparathyroidism. (A) Graph of average daily water consumption in model animals after surgery; (B) graph of average daily food intake in model animals after surgery (model vs. control Day2 $\left.{ }^{* *} \mathrm{P}<0.01, \mathrm{Day} 5{ }^{*} \mathrm{P}<0.05\right)$; $(\mathrm{C})$ graph of weight change in model animals after surgery (model vs. control Day1 ${ }^{* *} \mathrm{P}<0.01$, Day $2{ }^{* *} \mathrm{P}<0.01$ ); (D) graph of growth rate of body weight in model animals after surgery (model vs. control Dayl $\left.{ }^{* * *} \mathrm{P}<0.001\right)$; (E) results of serum PTH content measurement of model animals after surgery; (F) measurement results of serum calcium ion of model animals after surgery. PTH, parathyroid hormone.

concentration values (Figure $4 A$ ) of each group at the time of group assignment. After grouping, parathyroid cells were transplanted into different parts of rats (Figure $4 B$ ). The results showed that the water consumption of rats in the normal group was stable, but that of the gelatin sponge and model groups was higher than that of the normal group. The water consumption of rats in the subcutaneous transplantation and brachioradialis transplantation groups was close to that of the normal group but had a more flattened curve (Figure 4C). Similarly, the food intake of the rats of the normal group increased steadily, and that of the forearm brachioradialis group was closest to that of the normal group. Conversely, food intake in the model group decreased gradually over time, and food intake in the gelatin sponge and subcutaneous graft groups decreased significantly on day 25 post transplantation (Figure 4D); the reasons as to why this occurred require further analysis. There was no significant difference in the weight change of animals in each group after transplantation compared to the model group, and the animals in the model group gained weight more slowly than the animals in the normal group (Figure 4E). Compared to the normal control group without surgery, the percentage change in PTH in the model group animals showed a temporal progressive decrease, and on postoperative day 33, PTH decreased significantly; thus, the pathological changes were consistent with the clinical 

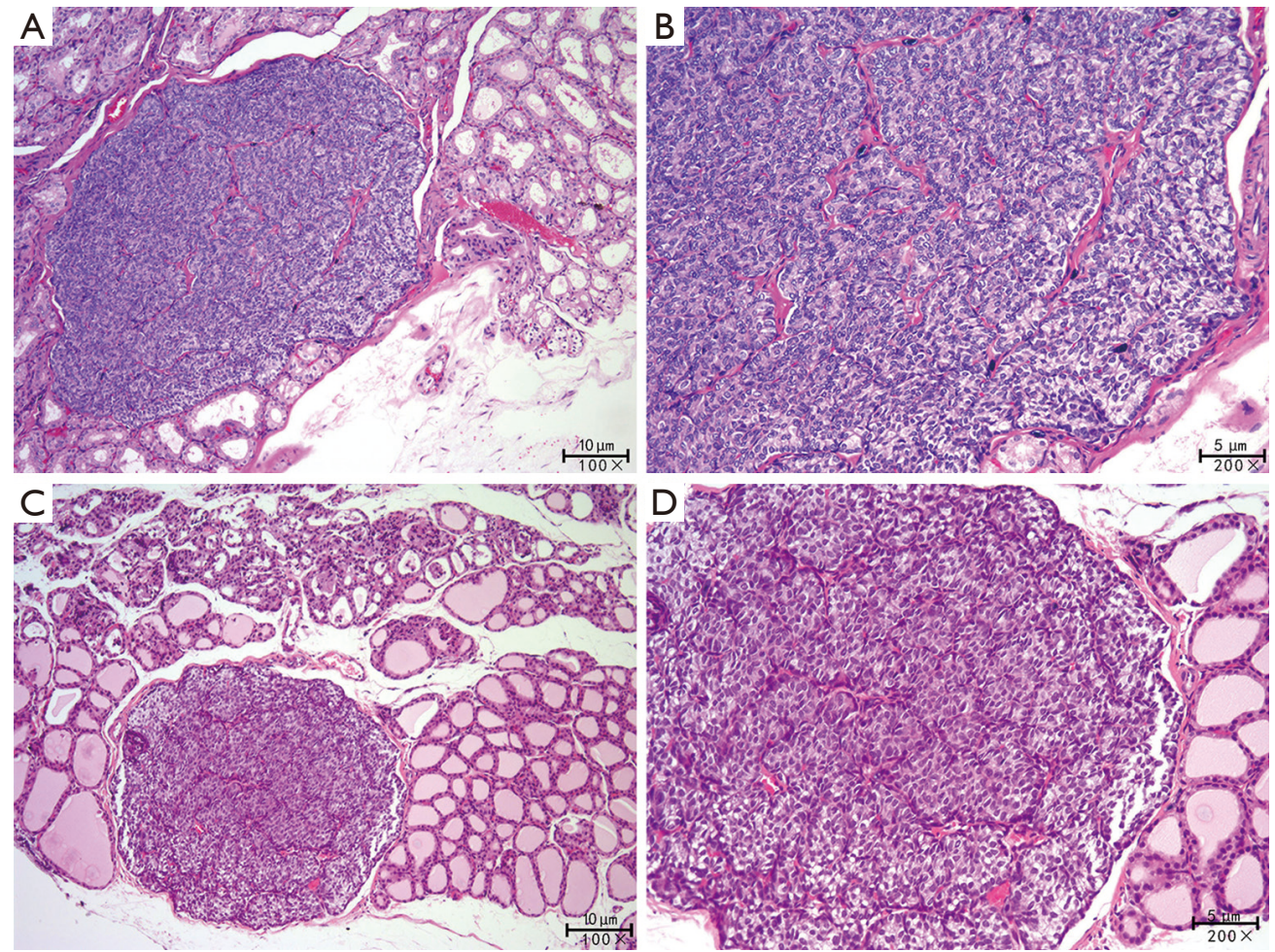

Figure 2 Microscopic view of the removed parathyroid gland in HE section. (A) Sample \#1 at 100×; (B) sample \#1 at 200×; (C) sample \#2 at 100×; (D) sample \#2 at 200×. HE, hematoxylin and eosin.

observations (Figure 4F). The 3 different transplantation methods had different effects on the restoration of PTH in animals; the right forearm intramuscular injection group had the most significant restoration of PTH in vivo after transplantation. By day 22 post transplantation, PTH secretion reached that of the normal control group, indicating that the transplantation site was effective. PTH secretion also reached the level of the normal group in subcutaneous transplantation group 22 days post transplantation.

Compared to the normal group, the percentage of serum calcium ions of the model group decreased significantly from day 1 to day 33 after surgery and remained at a lower level. The effect differed among the transplantation groups. On day 22 post transplantation, the serum calcium ion concentration of the subcutaneous transplantation group exceeded that of the model group, while the right forearm muscle graft group showed a significant increase in serum calcium from day 1 post transplantation and remained at a higher level for 33 days. Combining the results of serum PTH and serum calcium in all groups after transplantation (Figure 4G), $\mathrm{PTH}$ and serum calcium concentration in the right forearm muscle tissue increased in a short time after transplantation. The graft took effect early and could be maintained for 1 month. Interestingly, the subcutaneous graft group did not display the effect in the right forearm site; however the PTH and serum calcium levels were elevated from day 22 after transplantation and continued to increase with time, while the PTH and serum calcium levels in the right forearm graft site remained at the original levels. This finding requires further investigation in subsequent studies.

The safety of the grafts on the recipients was evaluated together with transplantation efficacy. Compared to the normal group animals, the model group animals showed a significant reduction in both the visceral index of the liver and the renal index, but there was no statistical differences among the normal group and transplantation groups, which shows the safety of the graft (Figure 5).

\section{Discussion}

The parathyroid gland is a small tissue in the human body, and an important endocrine gland. During clinical surgery 

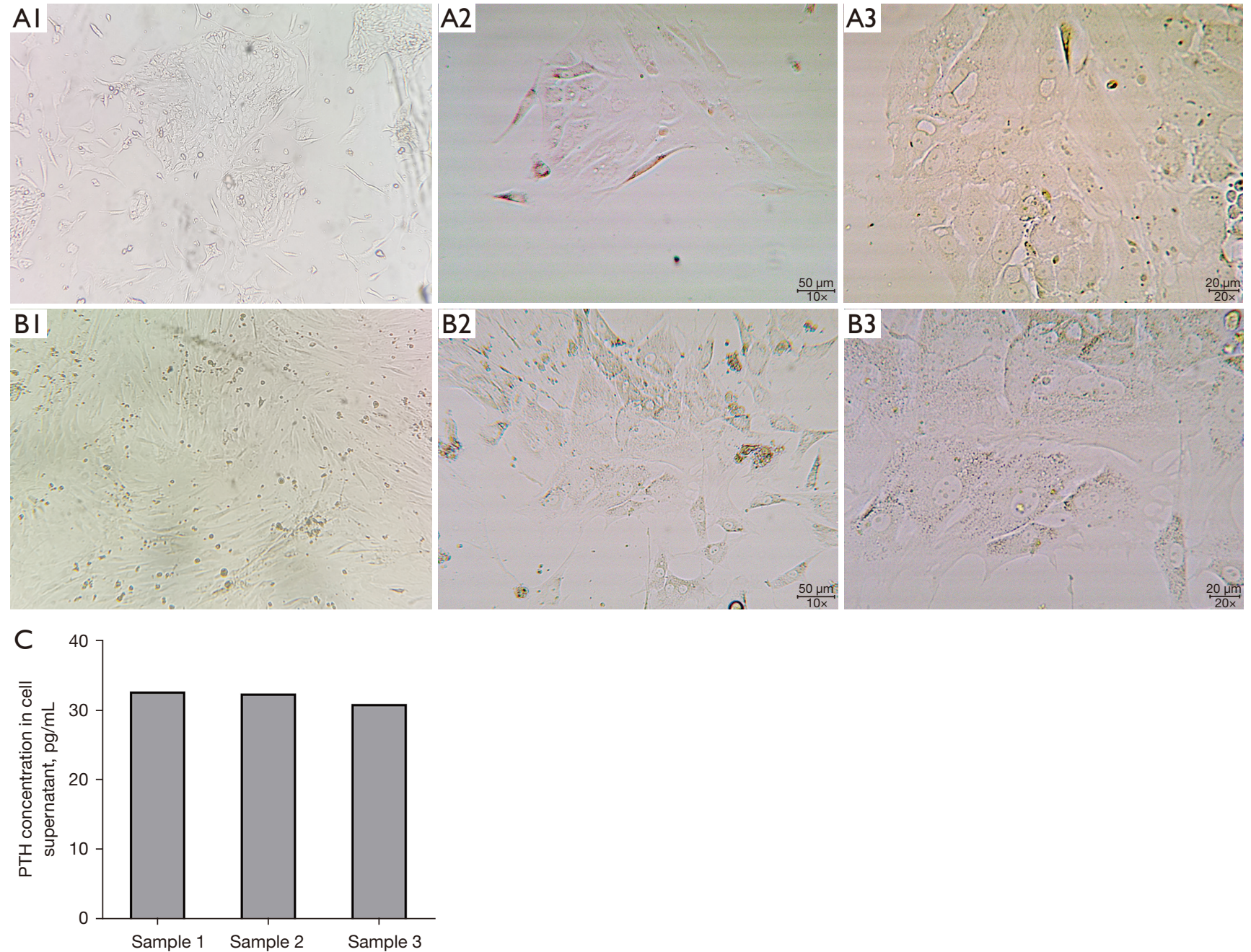

Figure 3 Primary culture of parathyroid cells. (A) A1: parathyroid cells in primary culture at day 6 under 4x; A2: parathyroid cells in primary culture at day 6 under 10x; A3: parathyroid cells in primary culture at day 6 under 20×, microscopic view. (B) B1: parathyroid cells in primary culture at day 9 under 4×; B2: parathyroid cells in primary culture at day 9 under 10x; B3: parathyroid cells in primary culture at day 9 under 20x, microscopic view. (C) Secretion of parathyroid hormone by cultured parathyroid cells. PTH, parathyroid hormone.

for thyroid cancer patients, the parathyroid glands are often removed during lymphatic dissection. During the process of thyroid membrane stripping or detachment by parathyroid traction, parathyroid spasm can also be caused, which can affect blood supply to the parathyroid glands. The resection of the parathyroid glands or insufficient blood supply may lead to hypoparathyroidism, low PTH secretion, and hypocalcemia, which can in turn lead to twitching or convulsions of the hands and feet and seriously affect the quality of life of patients postoperatively (18-20). In this experiment, consistent with clinical observations, animals with parathyroidectomy showed varying degrees of decreased PTH secretion and hypocalcemia. These animals were used as recipients for parathyroid cell transplantation.

Research on parathyroid transplantation has progressed slowly over the years. The transplantation methods currently available include tissue transplantation, vascularized thyroidparathyroid transplantation, and cell infusion transplantation. Compared with the first 2 transplantation methods, in vitro cultured parathyroid cells can reduce the immunogenicity of the graft, downregulate the expression of major histocompatibility complex-I (MHC-I) and MHC-II class antigens, control the number of transplanted cells, and regulate PTH content (21-23). Due to the characteristics of 

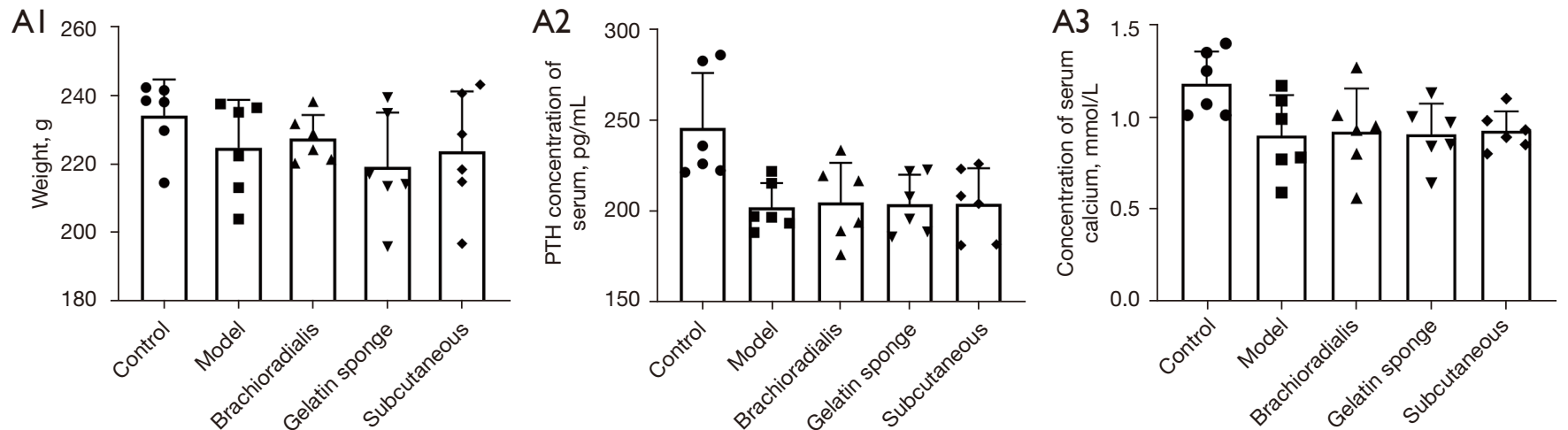
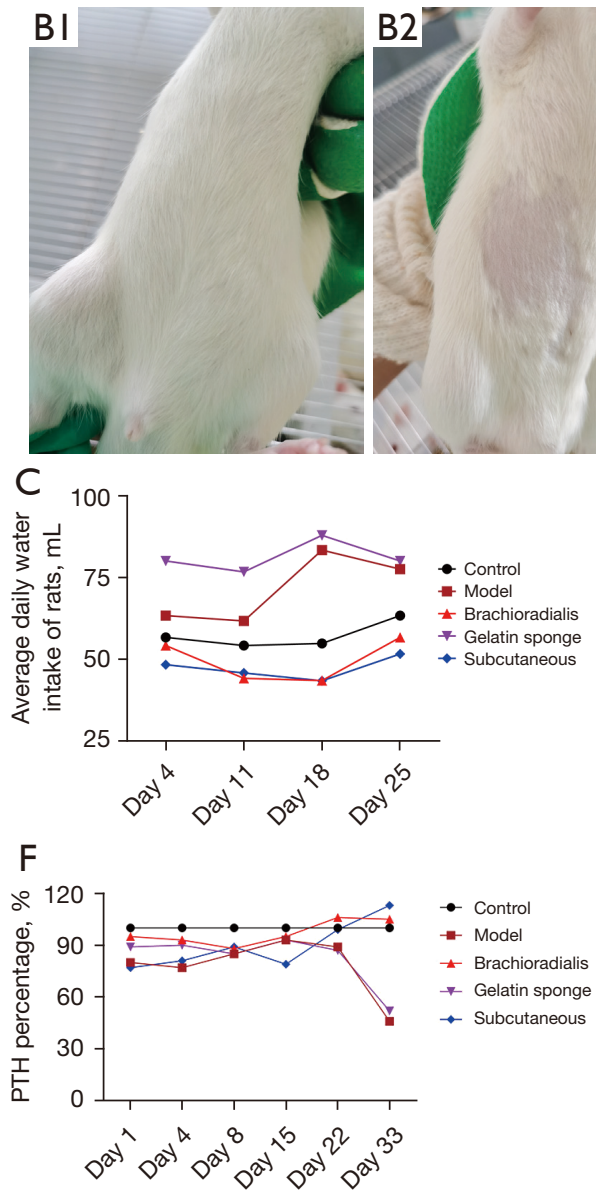

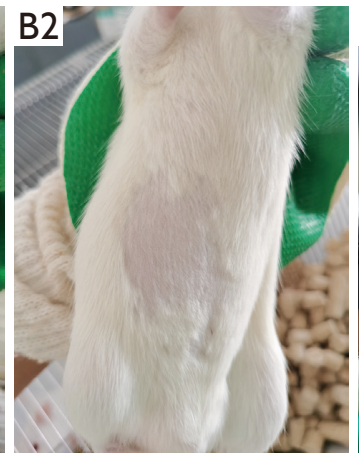

D

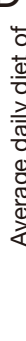

G

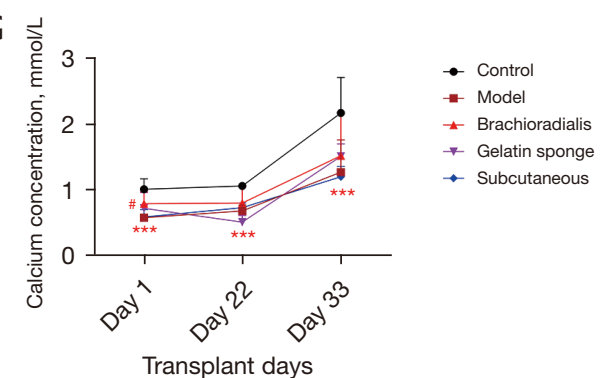

Figure 4 Comparative study of different transplantation methods and transplantation sites. (A1) Weight of each group at the time of group assignment; (A2) serum PTH values of each group at the time of group assignment; (A3) serum calcium ion concentration values of each group at the time of group assignment. (B1) Photograph of the abdomen of a recipient before transplantation; (B2) photograph of the abdomen of a rat in the subcutaneous cell transplantation group after transplantation; (B3) photograph of the abdomen of a rat in the gelatin sponge group after transplantation; (B4) local photograph of the brachioradialis muscle before transplantation; (B5) local photograph of the brachioradialis cell transplantation group after transplantation. (C) Change curve of the average daily water consumption for each group after transplantation; (D) change curve of the average daily food intake for each group after transplantation; (E) change curve of the body weight for each group after transplantation; (F) change curve of the serum PTH concentration for each group after transplantation; (G) change curve of the calcium ion concentration in serum for each group after transplantation. ${ }^{*} \mathrm{P}<0.05$, ${ }^{* * *} \mathrm{P}<0.001$ vs. Control; ${ }^{\#} \mathrm{P}<0.05$ vs. Model. PTH, parathyroid hormone. 

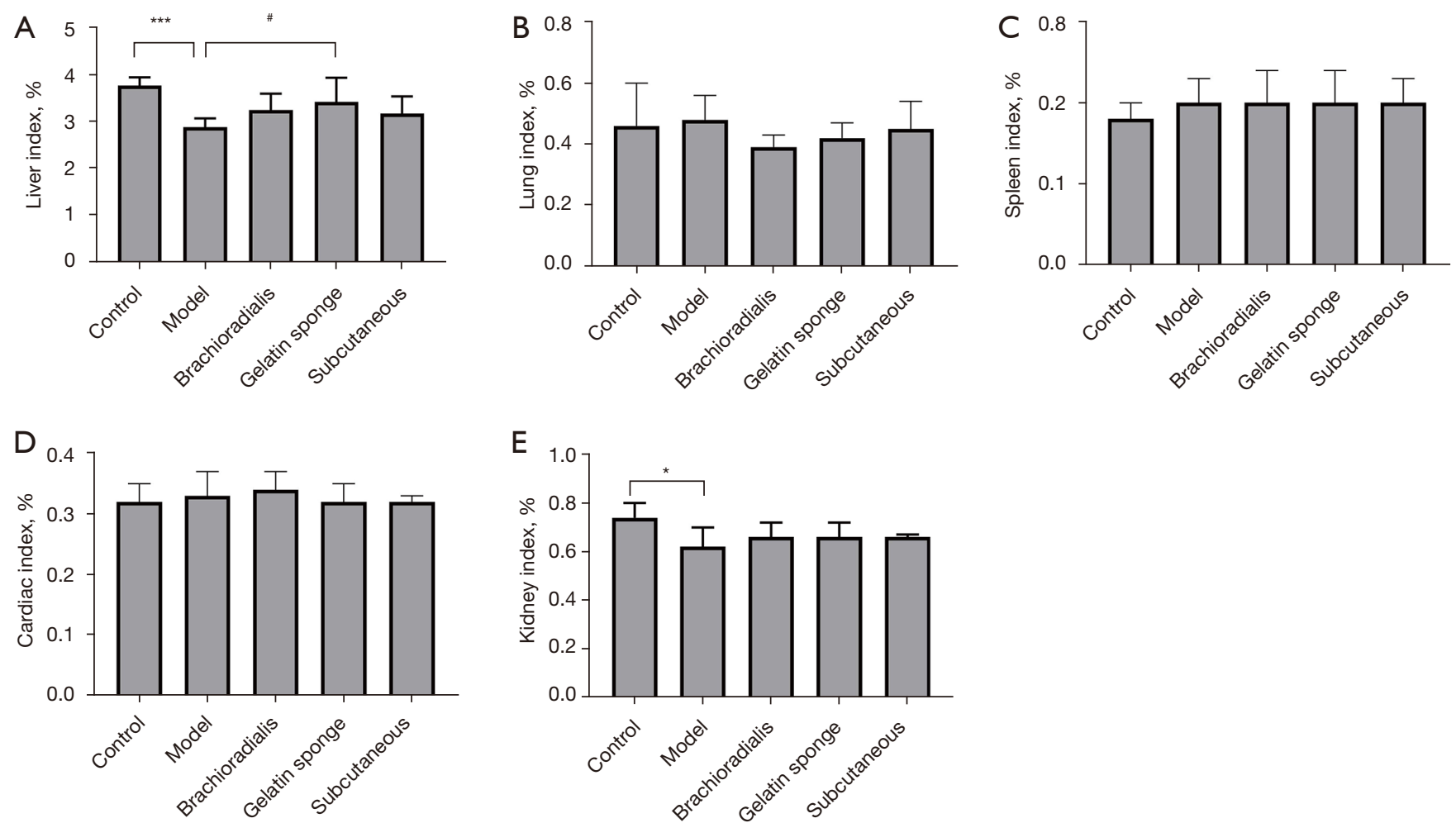

Figure 5 Organ indices of animals in each group after transplantation. (A) Liver index: normal group, model group, brachioradialis transplantation group, gelatin sponge group, and subcutaneous transplantation group. (B) Lung index (\%): normal group, model group, brachioradialis transplantation group, gelatin sponge group, and subcutaneous transplantation group. (C) Spleen index (\%): normal group, model group, brachioradialis transplantation group, gelatin sponge group, and subcutaneous transplantation group. (D) Heart index (\%): normal group, model group, brachioradialis transplantation group, gelatin sponge group, and subcutaneous transplantation group. (E) Renal index (\%): normal group, model group, brachioradialis transplantation group, gelatin sponge group, and subcutaneous transplantation group. ${ }^{*} \mathrm{P}<0.05,{ }^{* * *} \mathrm{P}<0.001$ vs. Control; ${ }^{~} \mathrm{P}<0.05$ vs. Model.

high survival rate, low immunogenicity, and repeated usage after cryopreservation, cell transplantation has developed rapidly in recent years. In terms of material selection, domestic and international studies have generally used patients with secondary hyperparathyroidism; however, primary parathyroid cells within 10 days of a culture are generally considered the best donors, but this resource is both difficult to obtain and limited in number. Previous investigators have also tried to use parathyroid adenoma tissue as the cell source, but fibroblast contamination occurred during the process of culture. To solve the difficulty of obtaining the donor source, in this study, we attempted to subculture the parathyroid primary cells and successfully obtained parathyroid cells with PTH secretion, which proliferated significantly from 6 days after primary digestion and had obvious secretion on day 9 , providing an important basis for cell transplantation of the parathyroid passages. Additionally, this study also attempted to transplant the third-generation allogeneic parathyroid cells back to different sites of the allogeneic recipient, providing a new idea for clinical allogeneic transplantation.

Microencapsulation technology has become an ideal vehicle for surgical transplantation for hypoparathyroidism because of its simplicity and ability to downregulate immune rejection without impeding the transport of nutrients and metabolites. Preliminary studies have shown that microencapsulated cell transplantation is more advantageous than cell transplantation alone $(24,25)$. However, there are also a number of problems with microencapsulated cell transplantation, including that: (I) some cells will be lost and damaged during the extraction of parathyroid cells and the preparation of microcapsules; 
(II) the microcapsular material may lead to the fibrosis of surrounding tissues; (III) the donors of allogeneic transplantation are often pigs, cattle, and other animals, which have a shorter life span than humans, and the proliferation cycle of glandular cells is also less than that of humans, resulting in poor long-term effects; (VI) cells that lose their normal surrounding environment may suffer from growth and proliferation issues; and (V) the long-term integrity of the current microcapsules cannot be guaranteed, and there is still a possibility of rejection after damage or rupture. Thus, to improve the duration of cells in the body after transplantation and to avoid a series of negative effects caused by the microcapsule technology, we observed and compared the effects of the transplantation of individual cells to that of carrier materials (gelatin sponge), and found that cell transplantation alone showed better performance than carrier materials (gelatin sponge) transplantation, which also provides ideas for the subsequent development of transplantation methods.

For the study of transplantation sites, researchers generally agree that the following conditions are required for an ideal transplantation site: high local oxygen partial pressure, a high degree of peripheral vascularization, and an immunologically privileged site (26). Currently, the commonly used transplantation sites are muscle, the abdominal wall, and the abdominal cavity $(27,28)$. Some researchers are of the view that muscle is the preferred graft site for microencapsulated transplantation due to its abundant blood supply and high oxygen concentration. This was confirmed in this study; the serum PTH and calcium ion concentrations were significantly increased in the brachioradialis muscle cell transplantation group compared to the model group. However, during the study, we found that the number of cells carried by the brachioradialis muscle was rather limited. To achieve the same amount of cells as that of the other transplantation groups, we used bilateral brachioradialis injections to compensate for the lack of cell volume. The subcutaneous transplantation could carry more cellular fluid, which prevented the abovementioned deficiency.

In addition, the results of serum PTH and serum calcium in all groups after transplantation were combined, and we found that PTH and serum calcium concentrations were elevated after transplantation in the right forearm muscle tissue within a short time, which took effect early and could be maintained for 1 month. In the subcutaneous transplantation group, the same effect in the right forearm transplantation was not achieved, but elevated PTH and serum calcium concentrations were observed on day 22 post transplantation. The PTH and serum calcium levels also continued to increase as time passed, while the PTH and serum calcium levels of the right forearm transplantation site remained at the original level over the same period. This interesting finding will be further investigated in subsequent studies.

Our study had several limitations. First, the study only extracted parathyroid tissue from male SD rats. Second, the sample size of this experiment was limited. Further studies on the prognostic value of allogeneic parathyroid cell transplantation will be conducted with expanding sample sizes in other different animal models.

In conclusion, this study provided a variety of convenient methods for parathyroid cell allografting. With the assistance of different transplantation sites and materials, the results of cell transplantation are guaranteed. This clinical solution provides a remedy for the series of problems caused by existing parathyroidectomy.

\section{Acknowledgments}

Funding: The study was supported by Beijing Tongren Hospital Fund for Distinguished Young Scholars (No.202001-ZY) and the Construction Project of Pudong Health Committee of Shanghai (Grant No. PWZy2020-06).

\section{Footnote}

Reporting Checklist: The authors have completed the ARRIVE reporting checklist. Available at https://dx.doi. org/10.21037/gs-21-809

Data Sharing Statement: Available at https://dx.doi. org/10.21037/gs-21-809

Conflicts of Interest: All authors have completed the ICMJE uniform disclosure form (available at https://dx.doi. org/10.21037/gs-21-809). The authors have no conflicts of interest to declare.

Ethical Statement: The authors are accountable for all aspects of the work in ensuring that questions related to the accuracy or integrity of any part of the work are appropriately investigated and resolved. Experiments were performed under a project license [No. SCXK (Beijing) 2019-0008] granted by the Ethics Committee of the Beijing Tongren Hospital, Capital Medical University, in 
compliance with the principles of the National Institutes of Health guide for the care and use of laboratory animals.

Open Access Statement: This is an Open Access article distributed in accordance with the Creative Commons Attribution-NonCommercial-NoDerivs 4.0 International License (CC BY-NC-ND 4.0), which permits the noncommercial replication and distribution of the article with the strict proviso that no changes or edits are made and the original work is properly cited (including links to both the formal publication through the relevant DOI and the license). See: https://creativecommons.org/licenses/by-nc-nd/4.0/.

\section{References}

1. Thomusch O, Machens A, Sekulla C, et al. The impact of surgical technique on postoperative hypoparathyroidism in bilateral thyroid surgery: a multivariate analysis of 5846 consecutive patients. Surgery 2003;133:180-5.

2. Lombardi CP, Raffaelli M, Princi P, et al. Parathyroid hormone levels 4 hours after surgery do not accurately predict post-thyroidectomy hypocalcemia. Surgery 2006;140:1016-23.

3. Fang L, Tang B, Hou D, et al. Relationship between parathyroid mass and parathyroid hormone level in hemodialysis patients with secondary hyperparathyroidism. BMC Nephrol 2015;16:82.

4. Noordzij M, Korevaar JC, Boeschoten EW, et al. The Kidney Disease Outcomes Quality Initiative (K/DOQI) Guideline for Bone Metabolism and Disease in CKD: association with mortality in dialysis patients. Am J Kidney Dis 2005;46:925-32.

5. Edafe O, Mech CE, Balasubramanian SP. Calcium, vitamin $\mathrm{D}$ or recombinant parathyroid hormone for managing post-thyroidectomy hypoparathyroidism. Cochrane Database Syst Rev 2019;5:CD012845.

6. Gafni RI, Guthrie LC, Kelly MH, et al. Transient Increased Calcium and Calcitriol Requirements After Discontinuation of Human Synthetic Parathyroid Hormone 1-34 (hPTH 1-34) Replacement Therapy in Hypoparathyroidism. J Bone Miner Res 2015;30:2112-8.

7. Shaha AR, Burnett C, Jaffe BM. Parathyroid autotransplantation during thyroid surgery. J Surg Oncol 1991;46:21-4.

8. Funahashi H, Satoh Y, Imai T, et al. Our technique of parathyroid autotransplantation in operation for papillary thyroid carcinoma. Surgery 1993;114:92-6.

9. Testini M, Gurrado A, Lissidini G, et al.
Hypoparathyroidism after total thyroidectomy. Minerva Chir 2007;62:409-15.

10. Agha A, Scherer MN, Moser C, et al. Living-donor parathyroid allotransplantation for therapy-refractory postsurgical persistent hypoparathyroidism in a nontransplant recipient-three year results: a case report. BMC Surg 2016;16:51.

11. Murua A, Portero A, Orive G, et al. Cell microencapsulation technology: towards clinical application. J Control Release 2008;132:76-83.

12. Bingham EL, Cheng SP, Woods Ignatoski KM, et al. Differentiation of human embryonic stem cells to a parathyroid-like phenotype. Stem Cells Dev 2009;18:1071-80.

13. Cui Q, Zhang D, Kong D, et al. Co-transplantation with adipose-derived cells to improve parathyroid transplantation in a mice model. Stem Cell Res Ther 2020;11:200.

14. Nawrot I, Woźniewicz B, Tołłoczko T, et al. Allotransplantation of cultured parathyroid progenitor cells without immunosuppression: clinical results. Transplantation 2007;83:734-40.

15. Anamaterou $C$, Lang $M$, Schimmack S, et al. Autotransplantation of parathyroid grafts into the tibialis anterior muscle after parathyroidectomy: a novel autotransplantation site. BMC Surg 2015;15:113.

16. Wells SA Jr, Gunnells JC, Shelburne JD, et al. Transplantation of the parathyroid glands in man: clinical indications and results. Surgery 1975;78:34-44.

17. Wells Jr SA, Ross 3rd AJ, Dale JK, et al. Transplantation of the parathyroid glands: current status. Surg Clin North Am 1979;59:167-77.

18. Saliba W, El-Haddad B. Secondary hyperparathyroidism: pathophysiology and treatment. J Am Board Fam Med 2009;22:574-81.

19. Chen L, Wang K, Yu S, et al. Long-term mortality after parathyroidectomy among chronic kidney disease patients with secondary hyperparathyroidism: a systematic review and meta-analysis. Ren Fail 2016;38:1050-8.

20. Apetrii M, Goldsmith D, Nistor I, et al. Impact of surgical parathyroidectomy on chronic kidney disease-mineral and bone disorder (CKD-MBD) - A systematic review and meta-analysis. PLoS One 2017;12:e0187025.

21. Schachter P, Christy MD, Leight GS Jr, et al. Function in athymic nude mice of parathyroid heterografts from patients with primary hyperparathyroidism and secondary hyperparathyroidism. Surgery 1990;108:1040-6.

22. Kadowaki MH, Fulton N, Schark C, et al. Difficulties of 
parathyroidectomy after previous thyroidectomy. Surgery 1989;106:1018-23, discussion 1023-4.

23. Tsuji K, Fuchinoue S, Kai K, et al. Culture of human parathyroid cells for transplantation. Transplant Proc 1999;31:2697.

24. Hasse C, Klöck G, Schlosser A, et al. Parathyroid allotransplantation without immunosuppression. Lancet 1997;350:1296-7.

25. Cabané P, Gac P, Amat J, et al. Allotransplant of microencapsulated parathyroid tissue in severe postsurgical hypoparathyroidism: a case report. Transplant Proc 2009;41:3879-83.

26. Wu G, Chang X, Xia Y, et al. Prospective randomized

Cite this article as: Niu Z, Huang S, Gao W, Yin G, Guo W, Huang J, Zhang Y, Huang Z. Promotion of allogeneic parathyroid cell transplantation in rats with hypoparathyroidism. Gland Surg 2021;10(12):3403-3414. doi: 10.21037/gs-21-809 trial of high versus low negative pressure suction in management of chyle fistula after neck dissection for metastatic thyroid carcinoma. Head Neck 2012;34:1711-5.

27. Tan CC, Cheah WK, Tan CT, et al. Intramuscular injection of parathyroid autografts is a viable option after total parathyroidectomy. World J Surg 2010;34:1332-6.

28. Zimmermann H, Zimmermann D, Reuss R, et al. Towards a medically approved technology for alginate-based microcapsules allowing long-term immunoisolated transplantation. J Mater Sci Mater Med 2005;16:491-501.

(English Language Editor: L. Huleatt) 